\title{
Appraisal of School-Based Stressors by Fourth-Grade Children: A Mixed Method Approach
}

\author{
Anjeli Agrawal $^{1}$, Rashmi Garg ${ }^{2 *}$, Diana Urajnik ${ }^{3}$ \\ ${ }^{1}$ Gulf Breeze Elementary, Santa Rosa County, Florida, USA; \\ ${ }^{2}$ Psychology Department, Laurentian University, Sudbury, Canada; \\ ${ }^{3}$ Department of Public Health Sciences, University of Toronto, Toronto, Canada. \\ Email: rgarg@laurentian.ca \\ Received August 23 $3^{\text {rd }}, 2010$; revised September $1^{\text {st }}, 2010$; accepted September $7^{\text {th }}, 2010$.
}

\begin{abstract}
This study examined appraisals of school-based stressors made by fourth-grade students. A mixed method approach was taken. School-based stressors were identified through focus group discussions and categorized into four domains (Academic, Peer Interaction, Teacher Interaction, and Discipline) through content analysis. A stress inventory was then constructed and administered to 54 fourth-grade students to assess the prominence of the identified stressor domains as well as any relationships between the stressor domains, academic standing, and gender. Results indicated that, on average, Peer Interaction and Discipline stressors were rated significantly higher than Academic and Teacher Interaction stressors. Furthermore, concerning all academic ability groups, girls rated stressors in all domains higher than boys. This higher rating proved to be significant for girls compared to boys with average academic ability regarding Peer Interaction stressors. The challenge for educators and policy makers is to identify situations that lead to stress as early as possible and design coping programs that will facilitate healthy development.
\end{abstract}

Keywords: School Based Stressors

\section{Introduction}

Stress has been defined as a reaction to a perceived imbalance between environmental demands and one's ability to deal with such demands (Lazarus \& Launier, 1978; Veno \& Davidson, 1978; Lazarus \& Folkman, 1984). Biologically, this reaction is an activation of neurobiological systems in an attempt to preserve allostasis, or a balanced state in the body (Gunnar \& Quevedo, 2007; Swearingen \& Cohen, 1985; Pareek, 1997). Although certain "optimal" levels of stress have been found to be beneficial, enhancing achievement and success (Selye, 1956), ongoing and unmanaged stress may increase an individual's risk for physical, emotional, mental, and behavioral problems (Gunnar \& Quevedo, 2007; Swearingen \& Cohen, 1985; Pareek, 1997).

The notion that young people experience stress and that stress reactions are directly related to their development, adjustment, and physical and emotional well-being, has been well documented in educational and clinical literature (Gunnar \& Quevedo, 2007; Kraag, Zeegers, Kok, Hosman, \& Abu-Saad, 2006; Carson, Swanson, Cooney, Gillum \& Cunningham, 1992; Blom, Cheney, \& Snoddy, 1986; Johns \& Johns, 1983; Schultze \& Heuchert, 1983; Phillips, 1978). One area that has received increased attention is the stress experienced by children in their school environment (D'Aurora \& Fimian, 1988; Omizo, Omizo, \& Suzuki, 1988; Humphrey, 1990; Barrett \& Heubeck, 2000; Jones-Sears \& Milburn, 1990; Karr \& Johnson, 1991; Bauwens \& Hourcade, 1992; Grannis, 1992). Researchers have reported that many children feel stressed about different aspects of school life (Greene, 1988; Bauwens \& Hourcade, 1992; Heubeck \& O'Sullivan, 1998). School-related demands, both academic and social, may be placed upon students by schools, parents, teachers, and peers (Omizo et al., 1988; Bauwens \& Hourcade, 1992). Some of these demands include: the evaluation process; difficulty understanding schoolwork; bullying; disciplinary procedures; adult expectations for success; and peer interactions.

School-based stressors have typically been categorized into different domains (Omizo et al., 1988; Bauwens \& Hourcade, 1992; Grannis, 1992; Barrett \& Heubeck, 2000; Philips, 1978). Phillips (1978) classified school-based stressors into two major categories: achievement stressors (such as, not receiving expected grades, teacher expectations, and comparisons with other students) and social stressors (such as, peers being unfriendly, or being teased or bullied by peers). Bauwens and Hourcade (1992) classified school-based stressors into eight categories including: school work; social interactions; treatment by teachers; discipline and classroom management procedures; extracurricular activities; public performances; and miscellaneous. Grannis (1992) classified school based stressors' frequency and appraisal into three categories in grade eight students: academic troubles (such as I could not finish work in class), physical and personal assaults (such as someone was picking at me) and general school disruptors (such as people in the classroom would not get quiet). Students reported general school disrupters as occurring more often than academic troubles, which they perceived slightly more often than physical and personal assaults. However students felt least upset by general school disrupters, most upset by physical and personal assaults, and almost as upset by academic difficulties.

The effects of school-based stressors on children's adjustment have not been well researched. The limited studies found investigating children on this subject (i.e., Heubeck \& O’Sullivan, 1998; Barrett \& Heubeck, 2000) suggested that 
school stressors are highly related to children's anxiety and conduct problems.

Gender and cultural differences in students' appraisals of school-based stressors have been noticed. According to Grannis (1992), females appraise stressors as more upsetting than males on subscales of academic troubles, physical and personal assaults, and general school disruption, and males' appraisals of stressors are significantly correlated with mean grade point average, but not females'. Regarding cultural differences, Grannis found that minority students generally experience more school-related stressors than mainstream students.

Studies demonstrating the negative effects of school stressors on students. Heubeck \& O' Sullivan, 1998; Barrett \& Heubeck, (2000) suggested that school stressors are highly related to children's anxiety and conduct problems. The effectiveness of school programs targeting stress management have mostly been based on early adolescent (middle school) and adolescent (high school) populations (i.e., Piekarska, 2000; Kraag et al., 2006; Meadows, Brown, \& Elder Jr., 2006). Although early adolescence has been viewed as a highly stressful period due to physical, cognitive, and social changes, Gunnar and Quevedo (2007) proposed that ages 7 through to 17 can be a "stress-hyporesponsive" period. This study focused on a population of elementary school children (grade 4) because it was believed that the nature and salience of school-based stressors for elementary school children may in fact be different from middle school and high school students.

Very few standardized instruments are available to measure school-based stressors. Of the few, School Situation Survey (SSS) by Helms and Gable (1989) uses an inventory of 34 items to assess four sources, and three manifestations, of school-related stress in grade 3 to grade 12 students. However, Gable, Ludlow, and Wolf (1990) questioned the construct validity of the SSS scale, saying it tends to lack differentiation among items, particularly with regards to the Academic Stress scale. Most other instruments have been adapted from life change experience inventories, personality and clinical scales, or they have been constructed by researchers for particular studies (Swearingen \& Cohen, 1985; Elias, Gara, Clabby, \& Schuyler, 1986; Dubow, Schmidt, McBride, \& Edwards 1993; Grannis, 1992; DeWolfe, 1995).

In this study, a mixed method approach (using both qualitative and quantitative methods) was used because qualitative inquiry facilitated an exploration of children's experiences of school-based stressors and quantitative method enabled us to test the salience of these stressors for males and females. In recent years, the mixed methods approach has gained acceptance and is now considered an important strategy of inquiry (Creswell, 2007). According to Stewart and Shamdasani (1990), the qualitative method of the focus group is particularly useful for exploratory research when there is little known about a phenomenon. This special type of group interview brings participants together to focus on, and explore the researcher's topic of interest in a guided way. Such group discussions are particularly effective because they involve a direct interaction between the participants, allowing the researcher to probe further into whatever issues arise in their conversation. Additionally, group dynamics can motivate group members to participate more openly compared to individual interviews (Stewart \& Shamdasani, 1990). In this study, focus groups were considered an ideal method of inquiry because they would allow children to speak freely about their experiences from their own understanding, personal beliefs and experiences. It was also believed that children would feel more comfortable in small group settings apposed to individual interviews.

Thus, this exploratory, descriptive, mixed method study was designed with two major aims. First: to gather fourth-grade children's descriptions of school-based stressors as they experience them; to use content analysis to categorize the stressors into themes or domains; and to construct a relevant questionnaire to be used as a tool to measure the relative importance of the stressor domains for children; and to assess any relationships between the stressors and children's academic standing and gender.

\section{Method}

\section{Sample}

Participants were 54 fourth-grade students ( 29 boys and 25 girls aged 9-10 years) taken from two classrooms of an elementary school located in the town of Pea Ridge, Florida. Twenty six students (14 boys and 12 girls) in the first classroom participated in focus group discussions, from which an inventory of school-based stressors was constructed. Fifty four students (29 boys and 25 girls) in two classrooms completed the inventory.

\section{Procedure}

\section{Qualitative Method}

After parental consent was obtained, 26 fourth-grade students were divided into four focus groups of five to seven participants. One of the focus groups was used for pilot testing. Any problems encountered in terms of procedure and scheduling, etc., were addressed prior to the actual data collection. The aim of the focus group component was to facilitate open discussion on what "bothers" or "worries" children when they are at school. The researcher remained open at all times to all concepts and variables that emerged during the discussions. Students were encouraged to talk to each other on the topics rather than always addressing the researcher. Their comments were explored in detail to make sure that the meaning had been understood. The aim was to "dig below the surface" of the topic and to discover any new ideas or themes that were not anticipated at the beginning of the research project. Each focus group session lasted for 40 to 50 minutes. Groups were led by a researcher and audio taped with the permission of the participants. At the end of each group session, participants were given the opportunity to speak with the researcher privately. None of the participants did so.

Content analysis was used to organize focus group data into prevalent themes of school stressors. The frequency with which the domains emerged was noted. Domains that were supported at least three times were used to develop a 33-item, three-point scale, questionnaire addressing school stressors. The questionnaire was pilot tested on seven students from the focus group for clarity of language and appropriate revisions were made. A panel of three judges categorized stressors into the following domains on a rational and intuitive basis: Academic, Peer Inte- 
raction, Teacher Interaction; Discipline; and Miscellaneous (Fairbank \& Hough, 1979; Lindenthal \& Mayers, 1979), as cited in Newcomb (Huba \& Bentler, 1981). Inter-rater reliability of .92 was derived from the categorical placement of items by the panel of judges.

\section{Quantitative Method}

The 33-item questionnaire was administered to a second group of 54 fourth-grade students. Each item was read aloud by the researcher while students followed the printed statements. The children were asked, "if this happens to you, how much would you be bothered by it?" One of the following choices could be selected: (1) it would not bother me; (2) it would bother me a little; (3) it would bother me a lot. An example of an item is "I do not make a good grade in my test". Administration time was approximately 30 minutes. Two weeks later, subjects were retested in the same way with the same stress inventory. Test-retest reliability was found to be .80 . For each participant, a stress index value for each item was calculated by averaging responses from the two administrations. Results are based on these stress indexes.

In addition to questionnaire responses, the students' grades on six subjects (reading, math, language skills, spelling, science, and social studies) of a recently taken standardized test (Comprehensive Test of Basic Skills) were obtained. Academic standing was calculated by averaging the grades of the six subjects. Three academic levels were created: (1) above average, or top one third; (2) average, or middle one third; and (3) below average, or bottom one third.

\section{Results}

Descriptive statistics for each domain of school-based stressors (Academic, Teacher Interaction, Peer Interaction, Discipline, and Miscellaneous) and for the 33 individual questionnaire items are presented in Table 1. Mean stress values for the Peer Interaction and Discipline domains were similar (2.68 and 2.50, respectively), while mean stress values for the Teacher Interaction and Academic domains were similar (2.05 and 2.0, respectively).Internal consistency (Cronbach's alpha) for the entire.

Table 1 .

Descriptive statistics for the school stress categories and 33 stress items (Based on $n=54$ subjects)**.

\begin{tabular}{|c|c|}
\hline School Event & Mean(SD) \\
\hline Academic & $2.01(.26)$ \\
\hline 1. I did not make a good grade on my test & $2.74(.45)$ \\
\hline 2. I could not get my work done because other kids were talking and cutting up & $2.61(.58)$ \\
\hline 3. I felt that other students understood the material being taught and I did not understand & $2.61(.50)$ \\
\hline 4. I was unable to complete my class work assignment & $2.52(.59)$ \\
\hline 5. My teacher made me stand up in the class to make a presentation in front of everybody & $2.22(.74)$ \\
\hline 6. I missed classroom instruction because I was either absent or tardy & $1.48(.73)$ \\
\hline 8. I had to take a test & $1.30(.56)$ \\
\hline 9. I had to do projects and reports at home & $1.22(.42)$ \\
\hline Peer Interaction & 2.67(.32) \\
\hline 10. Someone talked behind my back and said things about me which were not true & $2.87(.56)$ \\
\hline 11. Someone blamed me for something I did not do & $2.87(.56)$ \\
\hline 12. Someone called my mother, father, brother, or sister a name & $2.70(.64)$ \\
\hline 13. Kids talked nasty and used cuss words at me & $2.70(.64)$ \\
\hline 16. I was unable to make friends easily in school & $2.56(.37)$ \\
\hline 17. My best friend did not want to talk to me anymore & $2.57(.73)$ \\
\hline 18. someone pushed me or hit me for no good reason & $2.57(.59)$ \\
\hline 19. Kids called me names & $2.57(.66)$ \\
\hline 20. I was walking in line and other students tripped me & $2.57(.73)$ \\
\hline Teacher & 2.05(.47) \\
\hline 21. My teacher made fun of me or teased me in front of others & $2.64(.58)$ \\
\hline 22. My teacher likes another student in the class more than she likes me & 2.04(.99) \\
\hline 23. My teacher yelled at me & $1.87(.76)$ \\
\hline 24. My teacher corrected me in class & $1.70(.76)$ \\
\hline Discipline & $2.50(.43)$ \\
\hline 25. I was put in detention as a punishment for something I did and my parents had to come and get me & $2.83(.49)$ \\
\hline 26. My teacher sent a 'bad' note home for my parents & $2.70(.56)$ \\
\hline 27. The principal or assistant principal called my home to talk about a problem and complained about me & $2.70(.70)$ \\
\hline 28. My teacher received a complaint about me from special area school teachers like PE, Art or Music & $2.57(.59)$ \\
\hline Miscellaneous & $1.99(.40)$ \\
\hline 32. The school bus driver accused me for something I did not do & $2.58(.56)$ \\
\hline 33. I was taught by a substitute teacher & $1.54(.61)$ \\
\hline
\end{tabular}

** The items were randomly organized for the students. 
inventory was .83 . Alpha coefficients were reasonably high for Peer Interaction (.70) and Discipline (.80) domains, but were moderate to low for the Academic (.47) and Teacher Interactions (.43) domains. This could be due to the small sample size and relatively smaller number of items in these categories. Since no significant differences were found in two classes of grade four students with respect to any of the domains, the results are based on combined group of two classes.

One-way repeated analysis of variance (ANOVA) was performed on four domains of stressors (Academic, Teacher Interaction, Peer Interaction, and Discipline). The category of Miscellaneous stressors was dropped as it had only two items ("I was taught by a substitute teacher"; "Bus driver accused me of something which I did not do"). Results showed a significant difference among appraisals for the four domains of stressors, with $59 \%$ of the variance explained $\left(\mathrm{F}_{3,159}=31.04, \mathrm{p}<.001\right.$, Eta square $=.59$ ). Post-hoc pair-wise comparisons with adjusted alpha of .008 showed that children's appraisals of stressors were significantly higher for Peer Interaction and Discipline categories compared to Academic and Teacher Inter- action categories. Notably, most of the ten most highly app- raised school stressor items were located within the Peer Interaction domain (\# 10, 11, 12, 13, 14, 15), while three fell within the Discipline domain (\# 25, 26, 27) and one fell within the Academic domain (\#1). Likewise, half of the ten lowest appraisals of items fell within the Academic domain (\# 5, 6, 7, 8, 9), while three events fell within the Teacher Interaction domain (\# 22, 23, 24) and two fell within the Discipline domain (\# 30, 31).

A series of two-way analyses of variance (ANOVA) were performed to determine if differences in appraisals existed among the three academic levels (above average, average, and below average) and between genders with respect to the children's overall stress appraisal as well as stress appraisals in the four domains. Results showed no significant appraisal differences between academic levels or genders with regards to overall stress appraisals. However, regarding the Peer Inter- action domain, a significant gender by academic interaction was found $\left(\mathrm{F}_{2,48}=3.95, \mathrm{p}<.05\right)$, as well as a significant main difference between the three levels of academic standing $\left(\mathrm{F}_{2,48}=3.60, \mathrm{p}\right.$ $<.05$ ). Further analysis revealed that the below and above average ability groups appraised Peer Interaction stressors significantly higher than the average ability group. Additionally, among the children with average academic ability, girls gave significantly higher mean stressor appraisals than boys. However, since there was a small number of subjects in each gender by academic level group, these findings should be viewed with caution.

\section{Discussion}

The results of the present study confirm the existence of several categories of school based stressors: Academic, Peer Interaction, Teacher Interaction, Discipline, and Miscellaneous (Barrett \& Heubeck, 2000; Bauwens \& Hourcade, 1992; Grannis, 1992; Gable et al.,1990; Geisthardt \& Munsch, 1996). Although stressor items were independently categorized into domains with a high degree of reliability, one should keep in mind that domains were not confirmed through statistical analysis. The size of the sample precluded a factor analytic investigation using the total set of items. Results revealed that grade-four children appraise stressors in Peer Interaction and Discipline domains as being more stressful than Academic and Teacher Interaction categories. Nine of the ten items with the highest stress intensity values were located within the Peer Interaction and Discipline categories. Grannis (1992) has shown that stressors classified as "general disrupters" (such as noise in the classroom) were rated by students as occurring most frequently, but appraised as least upsetting, whereas assaults and academic troubles were appraised as more upsetting. Phillips (1978) categorized stressors into two categories, academic and social, where academic stressors were rated higher than social stressor. These results are contrary to the results found in this study. This may be due to two factors. That is, in the past 25 years, many changes in both social and family structure have taken place, such as: North American societies have become more multicultural; higher percentages of mothers are working full-time, outside of the home; and the number of single-parent households has increased. These factors may have influenced the importance of peer interactions. Researchers have found that students generally feel they have much more control over cognitive spheres compared to social spheres (Bethea, 1990 as cited in Grannis, 1992; Kragg et al., 2006). DeWolfe (1995) found that fears related to social adequacy and acceptance by peers prevail in school children. He reported the following three stressors as top stressors in a sample of grade 5 and 6 students: (1) being picked last for a team; (2) fear of peer disapproval; and (3) fear of not passing into the next grade. Elias, Gara, and Ubriaco (1985) found five categories of stressors, including: conflict relating to adult authority figures and peers; substance abuse; peer pressure and exclusion; rules for sociability relating to dating; friendships, etc.; and academic demands. In a meta-analysis of studies related to stress management in children and adolescence, Kraag et al. (2006) have described 12 studies dealing with stress management in elementary school children. Nine of these studies have focused on social problem solving.

Table 2.

Means, standard deviations, and ANOVA results of appraisal of stress for different categories of stressors by gender and academic standing.

\begin{tabular}{|c|c|c|c|c|c|c|c|c|c|c|}
\hline \multirow{2}{*}{$\begin{array}{l}\text { Components of stressors } \\
\text { Academic }\end{array}$} & \multirow{2}{*}{$\begin{array}{c}\text { Gender } \\
\text { Male female }\end{array}$} & \multicolumn{2}{|c|}{ Below Average Group } & \multicolumn{2}{|c|}{ Average Group } & \multicolumn{2}{|c|}{ Above Average Group } & \multirow{2}{*}{$\begin{array}{c}\begin{array}{c}\text { Academic } \\
\text { Standing Effect }\end{array} \\
\mathrm{F}_{2,48}=0.09\end{array}$} & \multirow{2}{*}{$\begin{array}{c}\begin{array}{c}\text { Gender } \\
\text { Effect }\end{array} \\
F_{1,48}=0.20\end{array}$} & \multirow{2}{*}{$\begin{array}{c}\begin{array}{c}\text { Interaction } \\
\text { Effect }\end{array} \\
\mathrm{F}_{2,48}=1.10\end{array}$} \\
\hline & & 1 & 0 & 1.89 & & & & & & \\
\hline teraction & e & 2 & $2.62(.18)$ & 1 & 2 & 2 & 2. & $\mathrm{~F}_{2,48}=$ & $\mathrm{F}_{1,48}=$ & 0.52 \\
\hline Peer Interaction & Male Female & $2.78(.17)$ & $2.55(.26)$ & $2.18(.47)$ & $2.70(.20)$ & $2.78(.19)$ & $2.84(.14)$ & $\mathrm{F}_{2,48}=3.60^{*}$ & $F_{1,48}=0.67$ & $\mathrm{~F}_{2,48}=3.95$ \\
\hline Dis & e & 2.5 & 2.8 & $1.86(.2$ & 2.6 & 2.7 & 2.4 & $\mathrm{~F}_{2}$ & $\mathrm{~F}_{1,48}=2$ & $\mathrm{~F}_{2,48}=3.14$ \\
\hline Overall & Male Female & $2.33(.28)$ & $2.39 .(17)$ & $1.92(.27)$ & $2.40(.09)$ & $2.38(.17)$ & $2.35(.18)$ & $\mathrm{F}_{2,48}=1.98$ & $\mathrm{~F}_{1,48}=3.06$ & $F_{2,48}=2.62$ \\
\hline
\end{tabular}

$* \mathrm{p}<.05$ 
It was expected that academic standing and gender may influence appraisals of overall stressors as well as the different domains. In this study, a higher number of boys than girls were in the below average academic category (50\% versus $20 \%$ ). Appraised stress level was found to be higher for girls than for boys in all domains. This higher rating was statistically significant for children with average academic ability regarding the Peer Interaction stressor domain. These findings support results obtained by Grannis (1992) that girls appraised stressors (negative events) as more upsetting than boys and received higher grades than boys. A weak correlation of .19 was found between academic performance and overall appraisal of stressors.

Results of the present study must be interpreted with caution. One cannot rule out the possibility of specificity of results to the current sample of children. Since students were required to respond to items based upon their own perceptions of stressful school events, it is possible that the stressors may vary in existence and strength as a function of various factors (i.e., type of school, particular teachers, SES, or personal variables). Results need to be replicated with a larger sample, including several classes of fourth-grade children from different schools in order to rectify these concerns. Future studies should also include information from different sources (teachers and parents, for example) to validate the inventory presented.

Ultimately, the challenge for society, educators, and educational administrators and policy makers is to identify problems that lead to stress for children as early as possible and to promote healthy development by teaching children about possible coping strategies. This study provided further data on schoolbased stressors and the salience of such stressors among children. This knowledge is valuable for future developments of stress prevention programs for children.

\section{References}

Barrett, S., \& Heubeck, B. G. (2000). Relationships between school hassles and uplifts and anxiety and conduct problems in grades 3 and 4. Journal of Applied Developmental Psychology, 21, 537-554 doi:10.1016/S0193-3973(00)00053-8

Bauwens, J., \& Hourcade, J. J. (1992). School-based sources of stress among elementary and secondary at-risk students. The School Counselor, 40, 97-102.

Blom, G. E., \& Cheney, B. D., \& Snoddy, J. E. (1986). Stress in childhood: An intervention model for teachers and other professionals. New York: Teachers College, Columbia University.

Carson, K., Swanson, D., Cooney, M., Gillum, B., \& Cunningham, D. (1992). Stress and coping as predictors of young children's development and psychosocial adjustment. Child Study Journal, 22, 273-301.

Creswell, J. W., \& Clark, V. L. P. (2007). Designing and conducting mixed method research. Thousand Oaks, CA: Sage Publications, Inc.

D'Aurora, D. L., \& Fimian, M. J. (1988). Dimensions of life and school stress experienced by young people. Psychology in the Schools, 25, 44-53. doi:10.1002/1520-6807(198801)25:1<44::AID-PITS231025$0108>3.0 . \mathrm{CO} ; 2-7$

DeWolfe, A. S. (1995). Stress reduction in sixth-grade students. Journal of Experimental Education, 63, 315-329. doi:10.1080/00220973. 1995.9943467

Dubow, E. F., Schmidt, J. M., McBride, J. \& Edwards, S.(1993). Teaching children to cope with stressful experiences: Initial implementation and evaluation of a primary prevention program. Journal of Clinical Child Psychology, 22, 428-440. doi:10.1207/s15374424 jccp2204 3

Elias, M. J., Gara, M., Clabby, J. F., \& Schuyler, T. (1986). Impact of a preventive social problem solving intervention on children's coping with middle-school stressors. American Journal of Community Psychology, 14, 259-275. doi:10.1007/BF00911174

Fairbank, D. T., \& Hough, R. T. (1979). Life event classifications and event illness relationship. Journal of Human Stress, 5, 41-47.

Gable, R. K., Ludlow, L. H., \& Wolf, M. B. (1990). The use of classical and Rasch latent trait models to enhance the validity of affective measures. Educational and Psychological Measurement, 50, 869878. doi:10.1177/0013164490504017

Geisthardt, C., \& Munsch, J. (1996). Coping with school stress: A comparison of adolescents with and without learning disabilities. Journal of Learning Disabilities, 29, 287-296. doi:10.1177/002221 949602900307

Grannis, J. C. (1992). Students' stress, distress, and achievement in an urban intermediate school. Journal of Early Adolescence, 12, 4-27. doi:10.1177/0272431692012001001

Greene, A. L. (1988). Early adolescents' perceptions of stress. Journal of Early Adolescence, 8, 391-403. doi:10.1177/0272431688084006

Gunnar, M., \& Quevedo, K. (2007). The neurobiology of stress and development. Annual Review of Psychology, 58, 145-173. doi:10.1146/annurev.psych.58.110405.085605

Helms, B. J., \& Gable, R. K. (1989). School situation survey. Palo Alto, CA: Consulting Psychologists Press, Inc.

Heubeck, B., \& O'Sullivan, C. (1998). An exploration into the nature, frequency and impact of school hassles in the middle school years. Australian Psychologist, 33, 130-137. doi:10.1080/0005006980 8257394

Humphrey, J. H. (1990). Research on childhood stress in the home and family, and school environments. In J. H. Humphrey (Ed.), Human stress: Current selected research (Vol. 4). New York: AMS Press.

Johns, B., \& Johns, M. (1983). Stress: It burns out kids too. Learning, 11, 48-49.

Jones-Sears, S., \& Milburn, J. (1990). School-age stress. In L. E. Arnold (Ed.), Childhood stress. New York: Wiley \& Sons.

Karr, S. K., \& Johnson, P. (1991). School stress reported by children in grades 4, 5, and 6. Psychological Reports, 68, 427-431. doi:10.2466/ PR0.68.2.427-431

Kraag, G., Zeegers, M. P., Kok, G.; Hosman, C., \& Abu-Saad, H. H. (2006). School programs targeting stress management in children and adolescents: A meta-analysis. Journal of School Psychology, 44, 449-472. doi:10.1016/j.jsp.2006.07.001

Lazarus, R. S., \& Folkman, S. (1984). Stress, appraisal, and coping. New York: Academic Press.

Lazarus, R. S., \& Launier, R. (1978). Stress-related transaction between person and environment. In L. A. Pervin \& M. Lewis (Eds.), Perspectives in interactional psychology, pp. 287-327. New York: Plenum.

Meadows, S. O., Brown, J. S., \& Elder Jr. G. H. (2006). Depressive symptoms, stress, and support: Gendered Trajectories from ado- lescence to young adulthood. Journal of Youth and Adolescence, 35 , 93-103. doi:10.1007/s10964-005-9021-6

Newcomb, M., Huba, C., \& Bentler, P. (1981). A multidimensional assessment of stressful life events among adolescents: Derivation and correlates. Journal of Health and Social Behavior, 22, 400-414 doi: $10.2307 / 2136681$

Omizo, M. M., Omizo, S. A., \& Suzuki, L. A. (1988). Children and stress: An exploratory study of stressors and symptoms. The School Counselor, 35, 267-274.

Pareek, U. (1997). Role stress and coping: A framework. In D.M. Pestonjee \& U. Pareek (Eds.), Studies in organizational role stress and coping (pp. 109-115). Jaipur: Rawat.

Phillips, B. N. (1978). School stress and anxiety: Theory, research, and intervention. New York: Human Science Press.

Piekarska, A. (2000). School stress, teachers' abusive behaviors, and children's coping strategies. Child Abuse and Neglect, 24, 14431449. doi:10.1016/S0145-2134(00)00201-5

Schultz, E. W., \& Heuchert, C. W. (1983). Child stress and school experience. New York: Human Science Press.

Selye, H. (1956). The stress of life. pp. 4-88, New York: McGraw-Hill. 
Stewart, D.W., \& Shamdasani, P. N. (1990). Focus groups: Theory and practice. Applied social research methods series, Thousand Oaks, CA: Sage Publications, Inc.

Swearingen, E., \& Cohen, L. (1985). Life events and psychological distress: A prospective study of young adolescents. Developmental Psychology, 21, 1045-1054. doi:10.1037/0012-1649.21.6.1045

Veno, A., \& Davidson, M. J. (1978). A relational model of stress and adaptation. Man-Environment System, 8, 75-89. 